\title{
Analysis on Consumer Demand of Electric Vehicle Based on Internet Survey
}

\author{
Yuhang Shang \\ College of Arts and Design \\ Beijing Forestry University \\ Beijing, 100083, P. R. China
}

\author{
Yi Feng* \\ College of Arts and Design \\ Beijing Forestry University \\ Beijing, 100083, P. R. China \\ fengyid@163.com \\ *Corresponding author
}

\begin{abstract}
Based on the online questionnaire and the analysis of the current materials, this paper carries out a market research on the consumers' awareness and purchase intention of the electric vehicles starting from the consumer behavior characteristics and consumption habits. It is found in the online investigation that consumers are less aware of most electric vehicles and their purchase intention is relatively simple. The design, price and reliability are the primary factors that consumers consider when purchasing an electric vehicle. Combined with the survey results, some suggestions are put forward for the development of electric vehicle for enterprises and manufacturers.
\end{abstract}

Keywords-market research; electric vehicles; consumer perception; consume intention

\section{INTRODUCTION}

Recent years have witnessed the rapid development of urbanization in China. Whereas the traffic has gone busier and busier with the soaring of the total amount of the vehicles. ${ }^{[1]}$ Bicycle, invented by a French named Sivrac in 1790, has now become the indispensable vehicles for people's life and work. However, the electric vehicles have spawned with great momentum, and gradually replaced the bicycles. ${ }^{[3]}$ Motorcycle, though possesses some advantages over electric vehicles, has been gradually replaced by the electrical counterparts as most cities have implemented the motor vehicle control policy. ${ }^{[4]}$

The electrical vehicle market is picking upstream, but the battery is still the shortcoming of the industry. [5] The competition is getting fierce, and sale channel, service and product quality grow mature. In the nationwide, there are multiple traditional electrical vehicles manufacturers like Yadea, Aima, Sunra and Luyuan, all of them possessing numerous franchisers. The online brand with a stunning rise like NIU, Ecooter, and Doohan are favored by the low age group. The founding teams of these brands carrying the Internet properties has attracted more citizen's attention in China's first and second tiered cities at they bring new riding experiences for the mass consumers, which can be attributed that they are skilled at digging targeted groups' demands, add intelligent technology into their original design and launch the reform on the traditional lead-acid battery with the adoption of lithium battery. ${ }^{[6]}$

This study was financially supported by the Fundamental Research Fund for the Central Universities (2018RW13) and the Fundamental Research Funds for the Central Universities (2015ZCQ-YS-01).

\section{STUDY PREPARATION AND QUESTIONNAIRE DESIGN}

\section{A. Research purposes}

At present, China has explored actively in the field of electric vehicles and played an important role in the international market. The electrical vehicle industry has shown slump these years after decades of remarkable development. What's worse, the competition gets fiercer, and products more similar, which make consumers reluctant to purchase new product versions. The traditional vehicle manufacturers are less attractive. Therefore, the key to the electric vehicle market research is the mass consumer. Explore the current design factors and their impact on the potential consumers in the electric vehicle market, and analyze the industry prospects and domestic market design direction.

\section{B. Research contents and methods}

The investigation acquires the information and suggestions mainly by the online questionnaire. The current electric vehicles are analyzed from the brand, appearance, price, driving mileage, intelligence, etc. A total of 73 questionnaires have been distributed, with all of them recollected.

\section{Questionnaire design}

The research object is the potential consumers of electric vehicles. An investigation of purchasing intention, product awareness and factors influencing the consumption is made on the respondents. The questionnaire is with clear logic and reasonable structure to facilitate the respondents to quickly understand the content of the questionnaire. The questionnaire structure is as follows:

\section{1) The Title}

The title of the questionnaire should be highly concise and summarize the survey topic. Therefore, the title of the questionnaire is "Questionnaire on Awareness and Satisfaction of Electric vehicles”.

\section{2) Information of interviewees}

This part includes information about the respondents' gender, age, occupation, education background, income, and marriage status, etc.

3) The main body of the questionnaire: the main body of the questionnaire includes the following aspects

a) Survey of potential consumers' awareness of the existing electric vehicles in the market. 
b) Survey of the daily use experience of people who currently own electric vehicles and the purchase intention of potential owners of electric vehicles.

c) Investigation of factors influencing the purchase of electric vehicles.

Multiple-choice questions are used to investigate the pain points in the design and riding experience of electric vehicles.

\section{SURVEY RESUltS STATISTICS AND ANALYSIS}

\section{A. Sample data description}

In the investigation, a total of 73 questionnaires have been distributed online, with all of them recollected usefully. The online questionnaire survey can produce more subjective results as it is not limited by space.

In the investigation, the male respondents account for $41.1 \%$ of the total, and female $58.9 \%$. When choosing the products, young people care more about the appearance and the reputation, while the aged think highly of reliability and comfort. Age can be a critical factor influencing purchasing. The majority of the respondents are aging between 20 and 30 , accounting for $75.34 \% .12 .33 \%$ falls within the range of 30 and 50 years old. Below 20 and above 50 are accounting for $9.59 \%$ and $2.74 \%$ respectively. The age proportion of respondents is shown in Fig. 1.

\begin{tabular}{|c|c|c|c|}
\hline Items & Subtota & & Proportion \\
\hline Below 20 years old & 7 & - & $9.59 \%$ \\
\hline 20 to 30 years old & 55 & 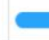 & $75.34 \%$ \\
\hline 30 to 50 years old & 9 & • & $12.33 \%$ \\
\hline Above 50 years old & 2 & 1 & $2.74 \%$ \\
\hline
\end{tabular}

Fig. 1. The age proportion of respondents

People that dwell in different areas, have different requirements of electric vehicles. In the light of the differences in economic structure and lifestyle of cities and rural areas, people that live in these regions have different acceptance of product functions. In the survey, the number of city dwellers is $57,78.08 \%$ of the total number. 16 are from rural areas, accounting for $21.92 \%$ of the total. The proportion of residence is shown in Fig. 2.

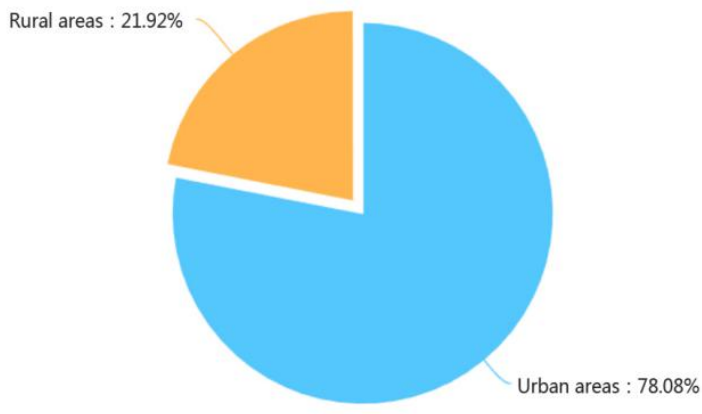

Fig. 2. The proportion of residence

Among all respondents, 31.51\% earn less than 2,000 Yuan monthly. 26.03\% have an income of 2,000 to 4,000 Yuan. $16.44 \%$ have an income of 4,000 to 6,000 Yuan. $9.59 \%$ have an income of 6,000 to 8,000 Yuan. 4.11\% have an income of 8,000 to 12,000 Yuan. $12.33 \%$ have an income of more than 12,000 Yuan. The salary proportion of interviewees is shown in Fig. 3.

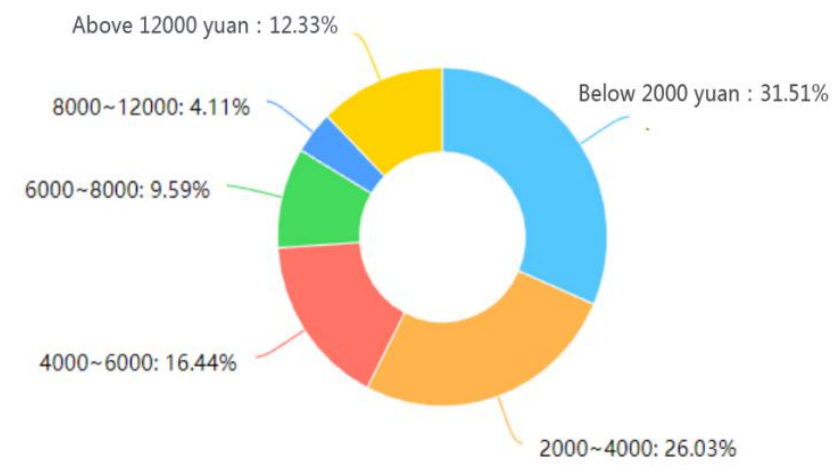

Fig. 3. The proportion of salary

The career may also influence the use form and use frequency of the product. In this research, 39.73\%, the majority of the respondents are students, and $19.18 \%$ are enterprise personnel. $10.96 \%$ are freelancers. Both teachers and the self-employed account for $5.48 \%$ of the total number of all. The smallest group is the civil servants, institution personnel and retirees, accounted for $1.37 \%$ of the total, and others occupy $15.07 \%$ of the total. The occupation proportion of interviewees is shown in Fig. 4.

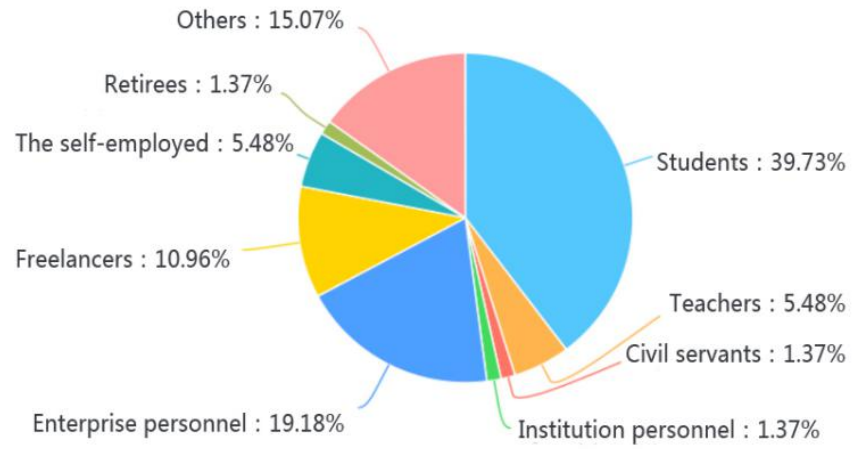

Fig. 4. The proportion of occupation

It is found in education is an important means for raising citizens' quality in modern society. The degree of education has an indirect influence on the consumption level, structure and opinion. The consumption pattern not only exerts great influence on the consumers and the families, but also greatly impacts the social-economic development. ${ }^{[2]}$ Most of the respondents hold a bachelor degree, accounting for $38.36 \%$ of the total. $23.29 \%$ of the respondents are graduated from the polytechnic school. The ones with the graduate degree account for $20.55 \%$ and doctoral degree $2.74 \%$. The proportion of education status is shown in the Fig. 5. 


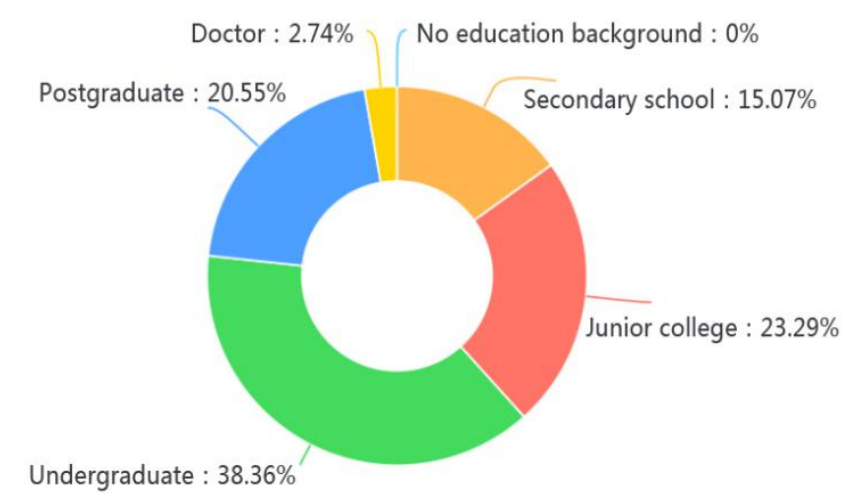

Fig. 5. The proportion of education status

\section{B. Analysis of consumers' consumption awareness of electric vehicles}

With the stunning rise of personal transport, more manufacturers are joining in the production of electric vehicles to take a share in the huge market. However, under the increasing competitive pressure, most of them stand still and make little effort in research and development and promotion. So, there are a few famous manufacturers in the market. Most electrical vehicle manufacturers, falling behind the market trend and time, can only struggle to survive. ${ }^{[7]}$

This survey investigated the electric vehicle brands that are familiar to the consumers, and sorted out the percentage of each brand awareness (i.e. the number of times the brand was selected by the respondents/the total number of respondents) as shown in Fig. 6. According to the survey, the top five are all well-known brands, namely Aima, Yadea, Sunra, Bird and Xiao Dao. Aima and Yadea were far ahead of Sunra in popularity. Aima ranks first with $87.67 \%$, Yadea ranks second with $86.3 \%$, Sunra ranks $56.16 \%$, Bird ranks fourth and Xiao Dao ranks fifth with $46.58 \%$ and $43.84 \%$ respectively.

Aima and Yadea have taken root in consumers' mind, which can be attributed to over ten years of market tests and experience accumulation. With good product quality and appropriate brand marketing, they have won a good product reputation over the years, making other manufacturers hard to shake their position in consumers' mind. Some companies don't pay attention to product marketing and brand promotion with less advertising, thus consumers rarely have the opportunity to contact and to know the brands with low popularity, such as the Slane, Jin Jian, Doohan, Ecooter, and Super Soco. These online internet brand electric vehicles rank at the bottom in terms of popularity in the survey.

It is worth noting that an internet brand, Niu, gains popularity of $28.77 \%$, close to the traditional electric vehicle manufacturers running for many years. As an emerging brand founded in 2014, NIU has achieved remarkable performance in a short period through the use of advanced technology, a unique marketing system, and gorgeous appearance. ${ }^{[8]}$ NIU has raised funding two times on the JD Finance, with the financing amounts of 72 million Yuan and 81 million Yuan respectively, creating a new milestone in product crowdfunding. An in-depth analysis shows that the design of its crowd funding business model is an important factor for the success of the brand. ${ }^{[9]}$ NIU has integrated multiple offline service outlets, established a consumer cooperation system, maintenance service system and door-to-door service system, which have been highly concerned by consumers, the electric vehicle industry and the Internet industry. ${ }^{[10]}$ The brand awareness percentage is shown in Fig. 6.

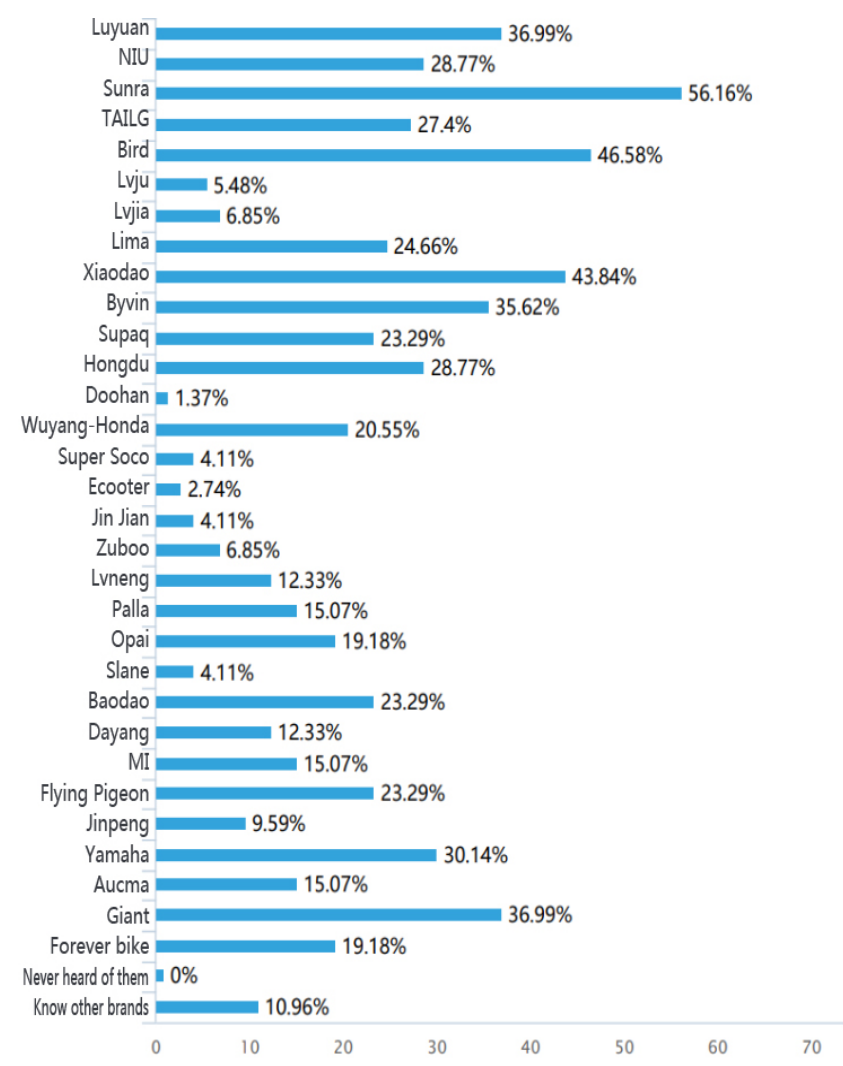

Fig. 6. Brand popularity percentage

As different vendors differ in publicity in different regions, consumers in different areas have different understandings towards the vehicles. It is found in the survey that Aima and Yadea gain more attention than any other brands whether in the city or the rural areas. In rural areas, the Aima's popularity has reached even $100 \%$, and Yadea $87.5 \%$. Whereas in cities, Yadea won by a narrow margin.

It is found in the survey that the emerging online brands enjoy a higher reputation in cities than in rural areas. The brand like NIU, Doohan, Ecooter and Super Soco, gain visibility index of $33.33 \%, 1.75 \%$, 3.51\% and 5.26\% in cities, and $12.5 \%$, $0 \%, 0 \%$ and $0 \%$ in rural areas. Only NIU are heard by the rural consumers and the rest are completely unknown by rural consumers. The brand awareness percentage value is shown in Fig. 7. 

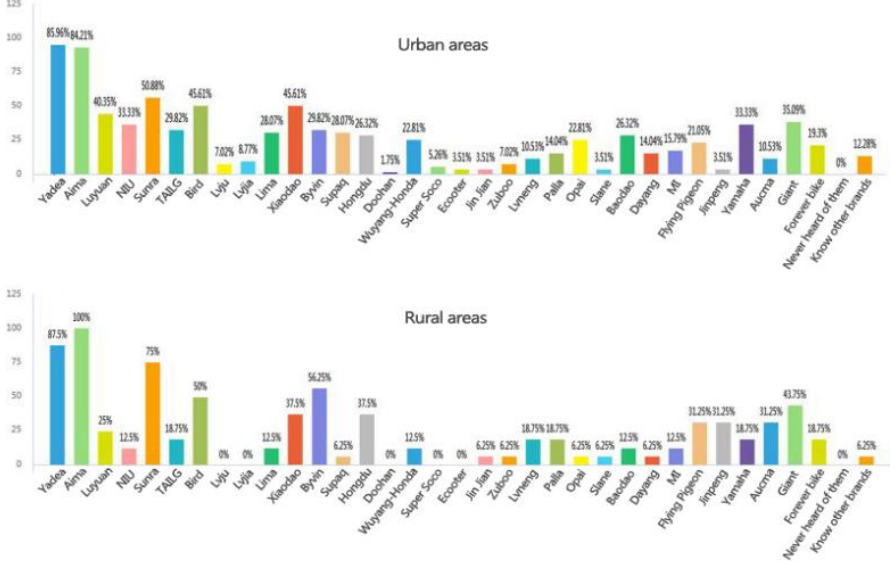

Fig. 7. The percentage of brand awareness

\section{Analysis of factors influencing consumers' purchasing}

This survey also investigated the intention of potential consumers when purchasing electric vehicles. $71.23 \%$ of them are interested in the ordinary potable facility. $21.92 \%$ prefer electric motorcycles. $4.11 \%$ are favor of foldable electric vehicles. Only $2.74 \%$ would like to buy the balance car. The types of electric vehicles that are preferred by the potential consumers are shown in the Fig. 8.

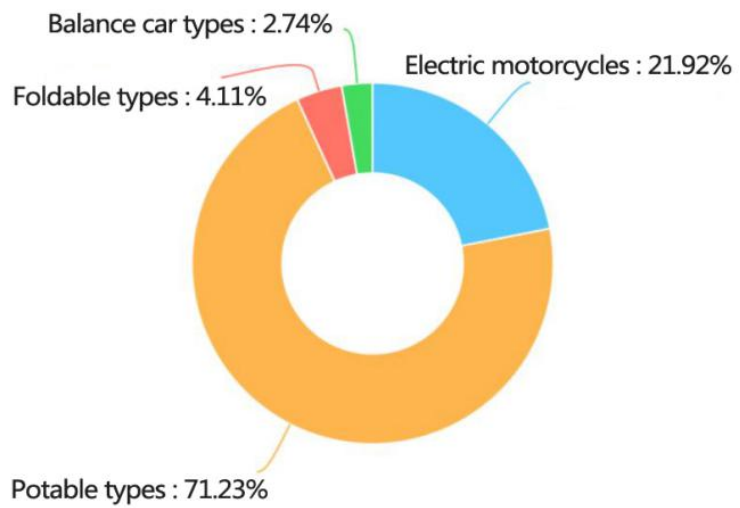

Fig. 8. Electric vehicles that consumers are intended to buy

In terms of factors influencing consumers' choice of vehicles, the questionnaire designs items like price, brand, appearance, reliability, new control, load capacity, driving mileage, rich functions, environment-friendly, strong power, intelligence, comfort, new lithium battery and after-sales service. According to the survey, the three factors most concerned by urban consumers are appearance (61.4\%), price (57.89\%) and reliability (45.61\%). And the three factors that rural consumers are most concerned about are appearance (50\%), controllability (50\%) and price (43.75\%). No matter in towns or villages, appearance is the aspect that consumers are most concerned about. Therefore, it can be seen that the appearance of a product, namely the design of a product, has a direct impact on the choice of the product. The product brands that consumers care about most are shown in Fig. 9.

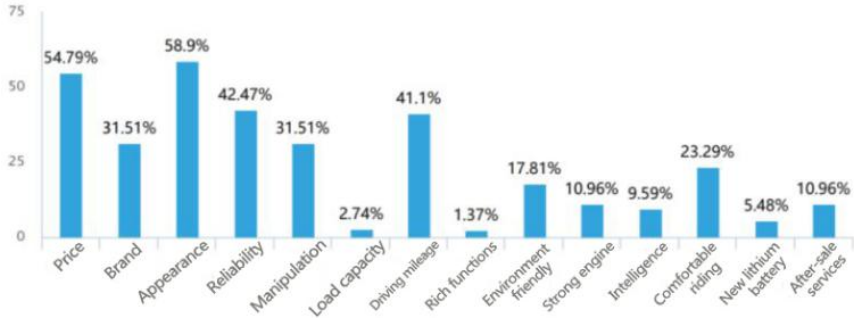

Fig. 9. Product brands what consumers care most about

\section{CONCLUSION}

With the continuous increase of the number of cars in cities, the traffic pressure in cities is also becoming intense. As the country delivers constantly the concept of energy conservation, emission reduction and green travel to the public, personal vehicles conforming to the concept of environmental protection gradually enters people's life. In the wave of consumption upgrading, consumers have turned from the pursuit of good quality and reasonable price to the pursuit of good design, fashionable appearance and high-quality service. In a word, price is no longer the first consideration when consumers buy products.

With the release of the new national standard for electric vehicles, the threshold of production gets higher. The industry may undergo reshuffle because of the rise in manufacturing costs. A growing number of small producers are risk of going out of business. Once the small producers disappear, the market share will be taken by big brands. In the end, the volume of the first-tier brands of electric vehicles will become larger and larger.

In recent years, the overall industry of electric vehicles has gradually grown towards intelligence, mobility and interconnection. With the increasing demand of consumers for electric vehicles, the role of electric vehicles is much more than just a means of transportation. Electric vehicles need to make breakthroughs and make innovations to cater to the changing market pattern and younger consumers. This will be the issue to be addressed in the future electric vehicle industry in a new stage of development.

\section{ACKNOWLEDGMENTS}

This study was financially supported by the Fundamental Research Funds for the Central Universities (2018RW13) and the Fundamental Research Funds for the Central Universities (2015ZCQ-YS-01).

\section{REFERENCES}

[1] Shi Hongbo, Zou Weina, Xu Yuping. Forecasting Analysis of the New Energy Vehicles Market from Green Technology Perspective: A Survey in Weihai, Shandong [J]Science and Technology Management Research.2014(8):227-232 (In Chinese)

[2] www.chinabgao.com. Statistical Analysis of Electric Vehicle Industry Data [EB/OL].http://www.chinabgao.com/k/diandongche/39465.html. 2018-09-10 (In Chinese)

[3] Zhang Hongtao. China’s Electric Vehicle Industry Development White Paper 2017 [EB/OL]. (In Chinese) 
http://ebike.zol.com.cn/662/6620040.html.2017-10-26

[4] Lv Chen. On the Business Model of Product Crowd funding in Chinese Context [J]Journal of Guizhou College of Finance and Economics.2017(3): 51-59 (In Chinese)

[5] Peter Wells, Xiao Lin. Spontaneous emergence versus technology management in sustainable mobility transitions: Electric bicycles in China [J] Transportation Research Part A: Policy and Practice.2015(78):371-383

[6] Yang Yulong. Efforts Required in the Implementation of the "New National Standard" for Electric Vehicles [J]China Business Times.2019-04-02 (In Chinese)
[7] Nianfeng Wan, S.Alireza Fayazi, Hamed Saeidi, Ardalan Vahidi. Optimal power management of an electric bicycle based on terrain preview and considering human fatigue dynamics[C]American Control Conference (ACC), 2014

[8] Hu Wanling, Zhu Shixuan, Wei Zhe, Huang Zhijia. Design Trend Research on Urban Personal Electric Vehicles of the Future[J]Journal of Brand Research.2018(05):37 (In Chinese)

[9] Wang Qian. Study on Industrial Design of Personal Electric Vehicles[J]Journal of Chifeng University.2014(15):32-33 (In Chinese)

[10] Wang Yao. Research on Electric Bicycle Design Based on Green Lifestyle[D]Huaqiao University 2014 (In Chinese) 